\section{Stereoscopic acuity for photometrically matched background wavelengths at scotopic and photopic levels*}

\author{
ROBERT H. YOUNG $t$ and ALFRED LIT \\ Southern minois University, Carbondale, Ilinois 62901
}

Two Ss made equidistance settings in a two-rod apparatus using white and four chromatic (red, yellow, green, and blue) backgrounds, photometrically matched at each of eight or nine test levels within a total retinal-illuminance range of $4 \mathrm{log}$ units. The binocular depth settings were analyzed in terms of the angular magnitude of both the variable error, $\eta_{A D}$, and the constant error, $\eta_{\Delta R}$. When $\eta_{A D}$ is plotted as a function of retinal illuminance, the curves for each of the four chromatic and white backround conditions show that at low retinal illuminances, $\eta_{A} D_{1}$ is initially large, and with increasing background illumination, $\eta \mathrm{p}$ progreasively decresues to approach a final low asymptotic value. As predicted by the duplicity theory of virion, each experimental curve show a discontinuity at about $-1.0 \mathrm{log}$ td (corresponding to a background luminance value of about $0.0059 \mathrm{fL}$ with the $2.5-\mathrm{mm}$ artificial pupil used) reflecting the transition from rod to cone functioning. The curves representing the different wavelengths essentially overlap throughout the total illumination range, indicating that, for both rod and cone vision, wavelength has no differential effect on the variability of depth settings. The data for $\eta_{\Delta R}$ are less regular than those for $\eta_{\mathrm{AD}}$, and the rod-cone discontinuities appear less pronounced. The data are analyzed in terms of the relative contribution of the rod and cone mechanisms to performance level.

Visual performance has long been known to be strongly affected by the prevailing level of retinal illuminance. Performance is characteristically poor at low scotopic levels and progressively improves as illumination is increased until the performance level reaches an asymptote at some high photopic illumination. In accordance with the duplicity theory of vision, a characteristic discontinuity occurs in the experimental curves which relate threshold response and retinal illuminance, reflecting the transition from scotopic (rod) to photopic (cone) functioning. If monochromatic stimuli are photometrically matched at some given photopic level, the cone segments of the experimental curves typically overlap, indicating that no differential wavelength effects in threshold response occur. The rod portions of the experimental curves are, however, progressively displaced toward the low end of the retinal-illuminance axis as stimulus wavelength is decreased, a result which is predicted by the differences in relative sensitivity of the scotopic and photopic luminosity functions. For

*This study was supported in part by research grants from the National Science Foundation (GB 2553) and the U.S. Public Health Service (NB Or617 and EY 00383) and $b y$ the Ofifice of Research and Projects, Southerm Inlnois University, awarded to Profeseor Alfed Iit.

+Present address: Department of Psychology, Ripon College, Ripon, Wisconsin 54971 . typical examples of such studies, see Hecht and Shlaer (1936) on critical flicker frequency; Hecht, Peskin, and Patt (1939) on luminance discrimination; and Shlaer, Smith, and Chase (1942) on visual acuity for red and blue light.

Stereoscopic depth-discrimination thresholds for black targets presented against a white background at scotopic and photopic levels of illumination have been systematically studied by several investigators (Hirsch \& Weymouth, 1948; Mueller \& Lloyd, 1948; Lit, 1959). The data presented by Lit (1959), for example, show a 20-fold increase in stereoscopic acuity as background illumination is in creased over $5 \mathrm{log}$ units. The characteristic rod-cone discontinuity is clearly exhibited in these data at about $-1.25 \log t d$.

The effect of stimulus wavelength on stereoscopic acuity has also been studied (Johns \& Sumner, 1948; Karwoski \& Lloyd, 1951; Edwards, 1955; Jonkers \& Kylstra, 1963; Vos, 1960; Kishto, 1965). However, none of these experiments systematically investigated the effect of stimulus wavelength for either target or background presented over a wide range of scotopic and photopic retinal-illuminance levels. Lit, Dwyer, and Morandi (1968) obtained such data using black targets presented against white and four chromatic backgrounds (red, yellow, green, and blue), photometrically matched at one photopic illumination level
(1.40 log $t d$ ). The stereoscopic threshold vs retinal-illuminance curves were in complete agreement with studies on the other visual functions mentioned above with respect to the overlapping of the photopic (cone) segments of the experimental curves and the systematic lateral separation of the scotopic (rod) segments as wavelength is decreased.

The present experiment is a direct extension of the earlier study by Lit, Dwyer, and Morandi (1968). Equidistance settings in the present experiment were obtained for black targets viewed against $a$ white and four chromatic backgrounds, each of which was photometrically matched at each level of illumination tested. It was performed concurrently with a companion study (Dwyer \& Lit, 1970), in which white and four chromatically illuminated targets were presented, on a black background, over a wide range of scotopic and photopic retinal-illuminance levels. Both experiments were designed to determine whether photometric matches performed at each scotopic and photopic test level would confirm the earlier study in demonstrating the absence of any differential wavelength effects on depth-discrimination thresholds at photopic levels; they would also provide new data assessing wavelength effects existing at subphotopic (i.e., scotopic and mesopic) levels.

Before the present and companion experiments had been performed, it was anticipated that for visual functions involving spatial resolution, equally bright stimuli of different wavelengths presented at mesopic levels would not necessarily result in equal acuity. Rather, the level of performance would be determined by the relative activity of the cone as compared to the rod system, for each of the chromatic stimuli, so that spatial resolution under red stimulation should be superior to that under an equally bright blue. This expectation was based on data (e.g., Walters \& Wright, 1943) which demonstrate that brightness matches made at one subphotopic level do not hold at all such levels, i.e., the shape of the luminosity function obtained at progressively lower mesopic levels exhibits a relatively greater increase in sensitivity for the short wavelengths as compared to that for the long. This would suggest that the relative activity of the rod system becomes greater for a blue stimulus than it does for an equally bright red one, the lower the mesopic level. At very low subphotopic retinal illuminances, where presumably only rods are functioning, a photometric match obtained at a single level should hold 
for that entire narrow range of scotopic illumination. On the basis of such considerations it was anticipated that, for both the colored target and colored background conditions, the stereoscopic threshold angle, $\eta_{A D}$, for photometrically matched stimuli at mesopic levels would be smaller for red than for blue illumination. At extremely low scotopic levels, where only the rod system is functioning, wavelength differences in spatial resolution should disappear.

The present experiment on background wavelength variations allows direct comparison with those recently reported in the companion study on target wavelength variations (Dwyer \& Lit, 1970), since the two Ss served in both experiments using the same experimental apparatus.

\section{METHOD}

Subjects

Two practiced Ss were used. One (R.W.) was emmetropic and the other (R.Y.) was myopic and wore corrective contact lenses; both had normal color vision (as measured by the H-R-R Pseudoisochromatic Plates) and normal binocular functioning. The interpupillary separation for R.W. was $6.5 \mathrm{~cm}$ and that for R.Y. was $6.4 \mathrm{~cm}$.

\section{Apparatus}

The apparatus 1 used in the present experiment has been fully described by Lit (1960). It is essentially similar to the two-rod device known as the Howard-Dolman apparatus (Howard, 1919). The standard target is a black vertical rod, $5.79 \mathrm{~mm}$ (0.33 deg) in diam, which is located at a distance of $100 \mathrm{~cm}$ in the upper half of S's visual field and laterally displaced $1.3 \mathrm{~cm}$ $(0.75 \mathrm{deg})$ to the right of his median plane. The comparison (fixation) target is a similar black vertical rod located in the lower half of S's visual field. $S$ can adjust its distance in his median plane; $E$ can measure this distance to an accuracy of $0.01 \mathrm{~cm}$. The bottom end of the upper (standard) target and the top end of the lower (variable) target lie in S's horizontal plane of fixation. $S$ is seated in an experimental darkroom and binocularly views the targets through a pair of circular artificial pupils, $2.5 \mathrm{~mm}$ in diam, and adjustable for interpupillary separation. A chinrest and foreheadrest are used to keep his eyes in alignment with the artificial pupils. Screening units provide a horizontal rectangular field of view, $22 \mathrm{deg} 4 \mathrm{~min} \times 2 \mathrm{deg} 42 \mathrm{~min}$. Background illumination is provided by a lightbox located in a frontal plane $250 \mathrm{~cm}$ from $S$. The retinal illuminance and wavelength of the background can be varied systematically by means of Kodak Wratten neutral density and colored filters placed in filter boxes mounted on the outer darkroom wall in front of each artificial pupil. The Wratten colored filters used were: No.72B (red), No. 73 (yellow), No. 74 (green), and No. 75 (blue) with maximum transmittances, as measured by a Beckman spectrophotometer, at about $603,572,530$, and $488 \mathrm{~nm}$, respectively.

\section{Procedure}

Prior to the main experiment, it was necessary to obtain a photometric match for the four chromatic backgrounds against the standard white background at each retinal-illuminance level used in the experiment. To accomplish this task, the "equivalent neutral-density" (END) values of each colored filter was determined at each illumination level. The procedure entailed the following operations. $S$ binocularly viewed the illuminated background in the experimental apparatus. Neutral density filters were placed in front of one eye, producing one of the retinal-illuminance levels (white light) to be used in the experiment. A chromatic filter was placed in front of $S$ 's other eye, and neutral density filters were added to that eye until he reported, by alternate monocular viewing, that the light appeared to be at the same brightness level as that of the white light. The END value of that colored filter, at the given illumination level, was determined by subtracting the value of the neutral density filters placed in front of the eye having the chromatic filter, from the value of the neutral density filters placed in front of the other eye. Thus, the END value of a colored filter represents the density of that neutral filter which would be required to replace the colored filter and still maintain the photometric match. The photometric matching procedure was repeated several times for each $S$ for the four colored filters at each illumination level.

The design of the main experiment called for 20 sessions, 4 sessions for the white and each of the four colored backgrounds. In each experimental session, R.W. made equidistance settings at nine illumination levels, ranging from -2.50 to $1.50 \log t d$ (corresponding to background luminances ranging from 0.00019 to $1.88 \mathrm{fL}) ; \quad$ R.Y. made equidistance settings at eight illumination levels, ranging from -2.00 to $1.50 \log t d$ $(0.00059$ to $1.88 \mathrm{fL})$. In each experimental session, a group of 14 equidistance settings was obtained at each retinal-illuminance level for each background condition. The illumination levels were always presented in ascending order of magnitude during an experimental session, following a $30-\mathrm{min}$ period of dark adaptation.

In performing an equidistance setting, $S$ fixated continuously on the top edge of the lower comparison target and adjusted its distance by "bracketing" until it appeared to lie in the same frontal plane as that of the upper target.

The equidistance settings were analyzed in terms of both the variable and constant errors. The variable error, designated as the stereoscopic threshold angle, $\eta_{A D}$, represents the angular transformation of the average deviation (AD) of the group of 14 equidistance settings obtained under a given condition of illumination. The constant error, $\eta_{\Delta R}$, represents the angular transformation of the average linear depth difference $(\Delta R)$ between the standard and the comparison target for the same group of settings.

\section{RESULTS AND DISCUSSION}

The average END values obtained for the two Ss under each background brightness-matching condition are given in Table 1 . The results are essentially identical to those obtained from the same $S s$ in the companion study on photometric matches for chromatic targets: at photopic levels (above about $0.00 \log$ td) the END values for all colored filters remained relatively constant. As the retinal illuminance of the standard white background is decreased below $0.00 \log t d$, the END values of the red and yellow filters increase, whereas those of the blue and green filters decrease. These findings are in complete agreement with expectations based on the difference between the scotopic and photopic luminosity functions, i.e., on the well-known increased sensitivity toward the blue end of the spectrum (Purkinje shift) which occurs as the visual system shifts from predominantly cone to predominantly rod functioning. Moreover, the constancy of the END values at high photopic levels appears to justify the usually used procedure of making photometric matches at only one photopic level on the assumption that the results of this match would hold at all photopic levels.

The data on the variable error, $\eta_{A D}$, as a function of background illumination are presented graphically in Fig. 1 for R.W. and in Fig. 2 for R.Y. The curves drawn through the data points which represent the different conditions of background illumination have been sketched by visual inspection. The data for both Ss 
Table 1

Average Equivalent Neutral Density (END) Values Obtained for Ss RW and RY at Each Llumination Level for Each of the Four Wratten Colored Filters

\begin{tabular}{|c|c|c|c|c|c|c|c|c|c|c|}
\hline & & \multicolumn{9}{|c|}{ Retinal Illuminance of White Background } \\
\hline & & -2.50 & -2.00 & -1.50 & -1.00 & -0.50 & 0.00 & 0.50 & 1.00 & 1.50 \\
\hline Red (72B) & $\begin{array}{l}\text { RW } \\
\mathbf{R Y}\end{array}$ & $\begin{array}{c}2.83 \\
-\end{array}$ & $\begin{array}{l}2.78 \\
2.82\end{array}$ & $\begin{array}{l}2.36 \\
2.51\end{array}$ & $\begin{array}{l}2.07 \\
2.30\end{array}$ & $\begin{array}{l}1.86 \\
2.02\end{array}$ & $\begin{array}{l}1.66 \\
1.79\end{array}$ & $\begin{array}{l}1.64 \\
1.79\end{array}$ & $\begin{array}{l}1.66 \\
1.72\end{array}$ & $\begin{array}{l}1.63 \\
1.59\end{array}$ \\
\hline Yellow (73) & $\begin{array}{l}\text { RW } \\
\mathbf{R Y}\end{array}$ & $\begin{array}{c}2.13 \\
-\end{array}$ & $\begin{array}{l}2.04 \\
2.10\end{array}$ & $\begin{array}{l}1.98 \\
2.04\end{array}$ & $\begin{array}{l}1.98 \\
2.00\end{array}$ & $\begin{array}{l}1.85 \\
1.87\end{array}$ & $\begin{array}{l}1.77 \\
1.77\end{array}$ & $\begin{array}{l}1.79 \\
1.63\end{array}$ & $\begin{array}{l}1.76 \\
1.69\end{array}$ & $\begin{array}{l}1.75 \\
1.62\end{array}$ \\
\hline Green (74) & $\begin{array}{l}\mathbf{R W} \\
\mathbf{R Y}\end{array}$ & $\begin{array}{c}1.16 \\
-\end{array}$ & $\begin{array}{l}1.00 \\
1.22\end{array}$ & $\begin{array}{l}1.07 \\
1.13\end{array}$ & $\begin{array}{l}1.22 \\
1.19\end{array}$ & $\begin{array}{l}1.37 \\
1.22\end{array}$ & $\begin{array}{l}1.30 \\
1.30\end{array}$ & $\begin{array}{l}1.25 \\
1.52\end{array}$ & $\begin{array}{l}1.26 \\
1.48\end{array}$ & $\begin{array}{l}1.25 \\
1.48\end{array}$ \\
\hline Blue (75) & $\begin{array}{l}\mathbf{R W} \\
\mathbf{R Y}\end{array}$ & $\begin{array}{c}1.30 \\
-\end{array}$ & $\begin{array}{l}1.24 \\
1.27\end{array}$ & $\begin{array}{l}1.12 \\
1.23\end{array}$ & $\begin{array}{l}1.43 \\
1.37\end{array}$ & $\begin{array}{l}1.58 \\
1.50\end{array}$ & $\begin{array}{l}1.60 \\
1.54\end{array}$ & $\begin{array}{l}1.58 \\
1.62\end{array}$ & $\begin{array}{l}1.55 \\
1.66\end{array}$ & $\begin{array}{l}1.64 \\
1.56\end{array}$ \\
\hline
\end{tabular}

show that $\eta_{A D}$ is large at low retinal illuminances for all background conditons and progressively decreases to approach a final asymptotic value slightly below about $10 \mathrm{sec}$ of arc as illumination is increased. A marked discontinuity in all experimental curves occurs at about -1.0 log td. This discontinuity, in the case of the white background, represents the transition from rod to cone vision. The observed discontinuities at the same retinal-illuminance value for all of the colored backgrounds results from the fact that the specification of the retinal illuminance of the colored backgrounds is based on photometric matches made against the white background. Thus, the discontinuity of the data for the colored backgrounds must occur at the same retinal-illuminance level as that of the white background, regardless of whether the response to the colored background was mediated by the rod or the cone system.

The experimental curves in Figs. 1 and 2 clearly overlap throughout the entire photopic and scotopic ranges. The overlapping of the photopic segments imply that background wavelength does not have a differential effect on stereoscopic acuity. This finding completely substantiates the data of the companion study (Dwyer \& Lit, 1970) on illuminated targets as well as those of the earlier study on background illumination (Lit, Dwyer, \& Morandi, 1968) in which photometric matches were made at only one photopic level by flicker photometry. It should be mentioned that the results of these three experiments on the independence of $\eta A D$ on target and background wavelength permit the use of equal stereoscopic acuity as an appropriate response criterion for specifying a constant visual effect for generating a photopic luminosity function, provided, of course, that the equidistance settings are obtained for a sufficient number of target or background wavelengths.

The overlapping of the subphotopic (mesopic and scotopic) segments of the curves in Figs. 1 and 2 are in complete agreement with the data of the companion study (Dwyer \& Lit, 1970) which used illuminated targets.

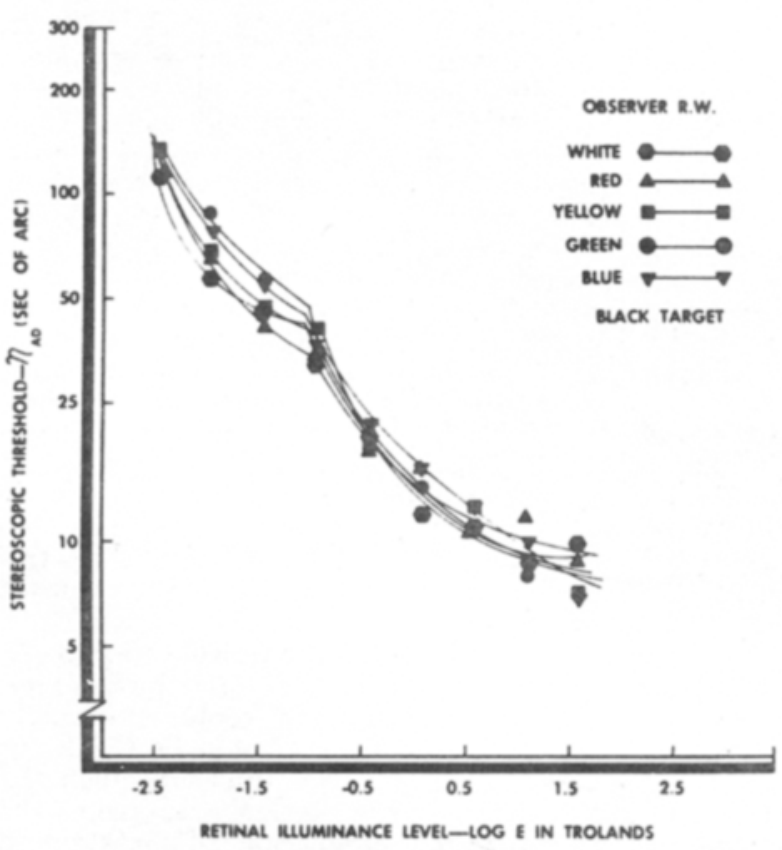

Fig. 1. Stereoscopic threshold angle, $\eta_{A D}$, as a function of retinal illuminance for $R$ W. The retingl ${ }^{\prime}$, as a function the colored backgrounds are specified on the basis of photometric math

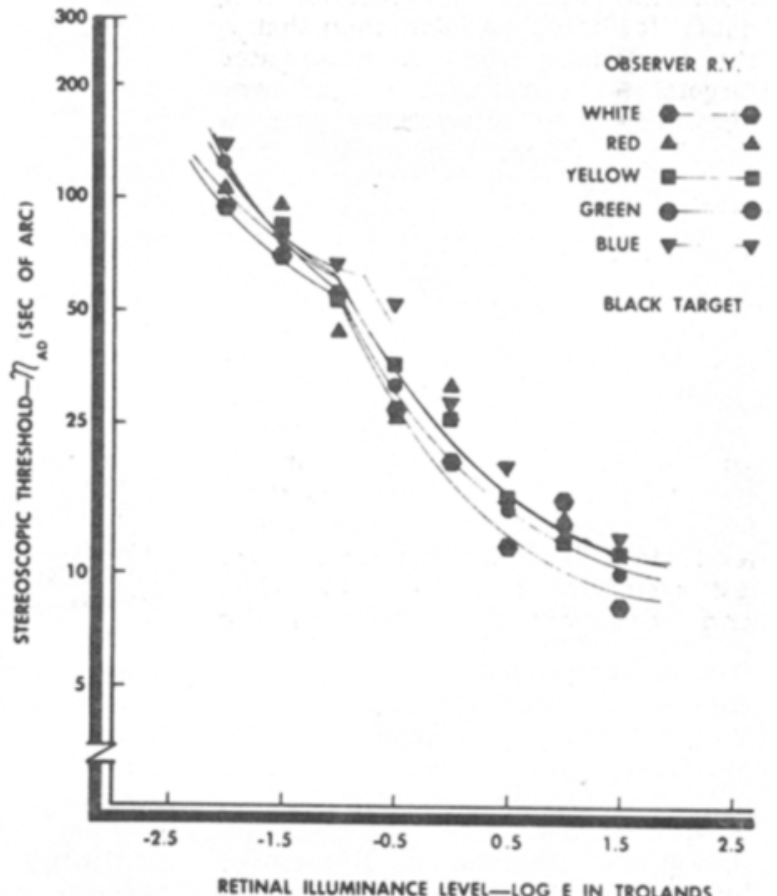

Fig. 2. Stereoscopic threshold angle, $\eta_{A D}$, as a function of retinal illuminance for $R . Y$. The retinal illuminance of the colored backgrounds are specified on the basis of photometric matches against white light at each of the indicated levels. 
Table 2

The Angular Constant Error, $\eta_{\Delta \mathbf{R}}$, for Each Background Wavelength and Retinal Dluminance Level*

\begin{tabular}{|c|c|c|c|c|c|c|c|c|c|c|}
\hline & & \multicolumn{9}{|c|}{ Retinal Illuminance ( $\log t d)$} \\
\hline & & -2.50 & -2.00 & -1.50 & -1.00 & -0.50 & 0.00 & 0.50 & 1.00 & 1.50 \\
\hline White & $\begin{array}{l}\mathbf{R W} \\
\mathbf{R Y}\end{array}$ & $\begin{array}{c}-31.3 \\
-\end{array}$ & $\begin{array}{l}-12.1 \dagger \\
-72.5\end{array}$ & $\begin{array}{l}43.4 \\
84.7\end{array}$ & $\begin{array}{l}73.6 \\
49.8\end{array}$ & $\begin{array}{l}55.1 \\
13.1\end{array}$ & $\begin{array}{r}25.3 \\
-22.1\end{array}$ & $\begin{array}{r}22.5 \\
-29.7\end{array}$ & $\begin{array}{r}16.2 \\
-23.9\end{array}$ & $\begin{array}{r}16.4 \\
-14.1\end{array}$ \\
\hline Red (72B) & $\begin{array}{l}\mathbf{R W} \\
\mathbf{R Y}\end{array}$ & $\begin{array}{c}-63.7 \\
-\end{array}$ & $\begin{array}{l}50.2 \\
41.4\end{array}$ & $\begin{array}{r}68.7 \\
9.3\end{array}$ & $\begin{array}{r}60.2 \\
8.5\end{array}$ & $\begin{array}{r}42.0 \\
-40.2\end{array}$ & $\begin{array}{r}33.2 \\
-17.0\end{array}$ & $\begin{array}{r}25.1 \\
-36.4\end{array}$ & $\begin{array}{r}12.7 \\
-38.6\end{array}$ & $\begin{array}{r}28.5 \\
-40.4\end{array}$ \\
\hline Yellow (73) & $\begin{array}{l}\mathbf{R W} \\
\mathbf{R Y}\end{array}$ & $\begin{array}{l}5.7 \\
-\end{array}$ & $\begin{array}{r}-18.7 \\
227.9\end{array}$ & $\begin{array}{l}71.2 \\
96.2\end{array}$ & $\begin{array}{r}98.1 \\
-7.7\end{array}$ & $\begin{array}{r}44.6 \\
-23.8\end{array}$ & $\begin{array}{r}33.4 \\
-29.1\end{array}$ & $\begin{array}{r}16.2 \\
-35.0\end{array}$ & $\begin{array}{r}28.9 \\
-28.4\end{array}$ & $\begin{array}{r}22.7 \\
-18.4\end{array}$ \\
\hline Green (74) & $\begin{array}{l}\mathbf{R W} \\
\mathbf{R Y}\end{array}$ & $\begin{array}{c}-40.0 \\
-\end{array}$ & $\begin{array}{r}-81.0 \\
106.1\end{array}$ & $\begin{array}{l}12.6 \\
76.9\end{array}$ & $\begin{array}{l}59.0 \\
25.0\end{array}$ & $\begin{array}{r}23.7 \\
-7.3\end{array}$ & $\begin{array}{r}38.2 \\
-37.6\end{array}$ & $\begin{array}{r}22.2 \\
-32.8\end{array}$ & $\begin{array}{r}8.5 \\
-34.9\end{array}$ & $\begin{array}{r}10.0 \\
-31.0\end{array}$ \\
\hline Blue (75) & $\begin{array}{l}\mathbf{R W} \\
\mathbf{R Y}\end{array}$ & $\begin{array}{c}-64.8 \\
-\end{array}$ & $\begin{array}{r}-66.5 \\
117.8\end{array}$ & $\begin{array}{r}3.9 \\
98.3\end{array}$ & $\begin{array}{l}46.7 \\
94.1\end{array}$ & $\begin{array}{r}68.0 \\
0.8\end{array}$ & $\begin{array}{r}24.1 \\
-8.7\end{array}$ & $\begin{array}{r}27.1 \\
-30.1\end{array}$ & $\begin{array}{r}18.7 \\
-22.8\end{array}$ & $\begin{array}{r}11.5 \\
-29.9\end{array}$ \\
\hline
\end{tabular}

*Each entry is based on the average of four groups of 14 equidistance settings for each $S$ (RW and $R Y$ ).

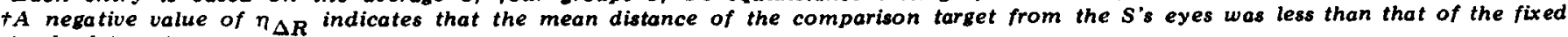
standard target.

Thus, for both classes of target-background illumination conditions, wavelength has no differential effects on depth discrimination thresholds at any retinal-illuminance level, provided the colored targets or backgrounds are photometrically matched at the specified level. No experimental data are available which explore possible differential wavelength effects at subphotopic levels for other visual functions (e.g., visual acuity, vernier acuity, etc.), where the responses are based on monocular spatial resolution. Similarly lacking are systematic data at subphotopic levels for monocular responses involving temporal resolution (e.g., CFF and reaction time data). It should be mentioned that in the companion study on illuminated targets, no wavelength effects were obtained when interference (narrow band pass) filters were used to vary stimulus wavelength.

The data on the angular constant errors presented in Table 2 show that the absolute values of $\eta_{\Delta \mathbf{R}}$ are initially high at low illumination levels and tend to decrease to values near zero as the level is progressively increased. The constant errors for $R$.W. are typically negative (i.e., the comparison target is set characteristically nearer than the standard) at low levels, whereas those for R.Y. tend to be positive at low levels. In general, the data for $\eta_{\Delta R}$ are less systematic than those for $\eta_{A D}$, and the rod-cone discontinuities appear less pronounced. The present experiment provides additional data to assist in the important task of identifying and evaluating the variables that are responsible for individual differences in the magnitude and direction of constant errors in equidistance settings.

\section{REFERENCES}

DWYER, W. O., \& LIT, A. Effect of luminance-matched wavelength on depth discrimination at scotopic and photopic levels of target illumination. Journal of the Optical Society of America, 1970, 60. $127-131$.

EDWARDS, A. S. Effect of color on visual depth perception. Journal of General Psychology, 1955, 52, 331-333.

HECHT, S.. \& SHLAER, S. Intermittent stimulation by light: $v$. The relation between intensity of critical frequency for different parts of the spectrum. Journal of General Physiology, 1936, 19, 965-977.

HECHT, S., PESKIN, J. C.. \& PATT. M. Intensity discrimination in the human eye: II. The relation between $\Delta 1 / 1$ and intensity for different parts of the spectrum. Journal of General Psychology, $1939,22,7.19$.

HIRSH, M. J., \& WEYMOUTH, F. W. Distance discrimination. Archives of Ophthalmology, 1948, 39, 210-223.

HOWARD, H. J. J. A test for the judgment of distance. American Journal of Ophthalmology, 1919, 2,656-675.

JOHNS, E. H., \& SUMNER, F. C. Relation of brightness differences of colors to their apparent distances. Journal of Psychology, 1948, 26, 25-29.

JONKERS, G. H., \& KYLSTRA, P. H. Brightness contrast in stereoscopic vision acuity. Ophthalmologica, 1963, 145, 139-143.

KARWOSK, T. F., \& LLOYD, V. V. Studies in vision: $V$. The role of chromatic aberration in depth perception.
Journal of General Psychology, 1951, 44, 159-173.

KISHTO, B. N. The colour stereoscopic effect. Vision Research, 1965, 5, 313-329.

LIT, A. Depth-discrimination thresholds as a function of binocular differences of retinal illuminance at scotopic and photopic levels. Journal of the Optical Society of A merica, 1959, 49, 746-752.

UIT A. Effect of target velocity in a frontal plane on binocular spatial localization at photopic retinal illuminance levels. Journal of the Optical Society of America, 1960, 50, 970-973.

LIT A., DWYER, W., \& MORANDI, A. The effect of background wavelength on stereoscopic acuity at scotopic and photopic levels of illumination. American Journal of Optometry, 1968, 45, 195-203.

MUELLER, C. G. \& LLOYD, V. V Stereoscopic acuity for various levels of illumination. Proceedings of the National Academy of Sciences, 1948, 34, 223-227.

SHLAER, S., SMITH, E. L., \& CHASE, A. M. Visual acuity and illumination in different spectral regions. Journal of General Physiology, 1942, 25, 55 3-569.

VOS. J. J. Some new aspects of color stereoscopy. Journal of the Optical Society of America, 1960, 50, 785-790.

WALTERS, H. V., \& WRIGHT, W. D. The spectral sensitivity of the fovea and extra-fovea in the Pukinje range. Proceedings of the Royal Society (London), 1943, 131B, 340-361.

\section{NOTE}

1. The apparatus was originally constructed at Pupin $L$ aboratories. Columbia University, partially through funds from a research grant-in-aid provided to Professor Lit by the American Academy of Optometry.

(Received for publication September 23, 1971.) 